\title{
Study on the adhesion performance of medium weathered igneous rock aggregate and asphalt
}

\author{
Xuxue Jiao ${ }^{1}$, Yuanhong Tao ${ }^{1}$, Longfang Ren ${ }^{2, *}$ \\ ${ }^{1}$ China Road and Bridge Co., Beijing 100011, China \\ ${ }^{2}$ China Academy of Building Research, Beijing 100013, China
}

\begin{abstract}
In view of the current situation of the shortage of alkaline aggregate and the abundance of weakly acidic weathered igneous rocks around Nairobi, Kenya, in order to fully improve the adhesion performance of asphalt and acidic igneous rocks, this paper studies the effects of different anti-stripping agents separately and combined on the adhesion performance of asphalt aggregates. The results show that the anti-stripping agent can improve the anti-stripping property of the medium weathered igneous rock aggregate and asphalt, and the effect is better when the anti-stripping agent is combined.
\end{abstract}

\section{Introduction}

The state promotes the construction of "One Belt And One Road". Nairobi Expressway in Kenya is one of the important projects of infrastructure construction in East Africa. The rocks in Nairobi and its surrounding areas are mainly weakly acidic moderately weathered igneous rocks, other rock yards are far away. The medium weathered igneous rocks along the highway will be used in the project construction.

At present, asphalt pavement is widely used in road construction. With the extension of service life, the expressway faces different forms of damage, which will greatly reduce the pavement performance. Water damage is one of the main early diseases of asphalt expressway, which is easy to cause loose, exposed and poth of pavement. The adhesion between asphalt and aggregate is one of the important indexes to evaluate the resistance of asphalt pavement to water damage.

The asphalt material is slightly acidic, it has good adhesion to alkaline stone, but poor adhesion with acid stone. Under the action of water, the asphalt is easily stripping, which leads to water damage of asphalt pavement. Due to the scarcity of available alkaline stone around the project site, long-distance transportation will greatly increase the cost of the project, so this method is not advisable. Considering the rich reserves of weak acid igneous rocks around the project site, the anti-stripping treatment can be adopted to improve the adhesion between medium weathered igneous rocks and asphalt, and a large amount of igneous rocks around the site can be utilized to ensure the quality of the project and reduce the project cost.

Adding anti-stripping agent is one of the common methods to improve the adhesion of asphalt aggregate. Traditional inorganic anti-stripping agent include cement and slaked lime which are less costly but its applying process is complex and it is difficult to mix evenly. Chemical anti-stripping agents include amines and nonamines, mostly amines, This kind of anti-stripping agent mainly achieves the anti-stripping effect by combining its polar group with acid aggregate and its oil-friendly group with asphalt [1]. It has the advantages of easy to use and easy to mix evenly, but it also has the problem of high cost.

A great deal of research has been done on the application of anti-stripping agents at home and abroad. Tan Jizong [2] verified that granite asphalt mixture can reach the road performance index of limestone asphalt mixture after adding anti-stripping agent. The study of Zheng Xiaoguang [3] shows that cement instead of mineral powder can greatly improve the high temperature stability and water stability of asphalt mixture. The study of Wei Zepeng et al. [4] shows that the water stability of asphalt mixture can be improved when cement replaces $20 \% \sim 40 \%$ mineral powder.

The study of anti-stripping agents at home and abroad mainly focuses on the improvement of pavement performance, water stability and temperature stability.In this paper, the stripping rate of asphalt on the surface of medium weathered igneous aggregate is studied by using quantitative analysis method and single or multiple antistripping agent for asphalt aggregate. It provides theoretical basis for water resistance measures of asphalt pavement.

\section{Materials and Methods}

\subsection{Raw Materials}

(1) Aggregate: the aggregate used in this experiment is medium weathered igneous rocks in Nairobi and its surrounding areas. The rock is processed into coarse and

* Corresponding author: 13051185882@163.com 
fine aggregate by laboratory small jaw crusher. The chemical composition of stone powder with particle size of $0-0.075 \mathrm{~mm}$ was analyzed by chemical titration. According to GB/T 14685-2011, test the compressive strength, apparent density, soundness and crushing value of aggregates with particle size of $5-20 \mathrm{~mm}$. The technical indicators are shown in table 1.

(2) Asphalt: the asphalt used in this test is road petroleum asphalt 70 and SBS modified asphalt. The technical indicators are shown in table 2.

(3) Cement: The Cement used in this experiment is CEMI 42.5 which produced in Kenya, its setting time is initial 165 minutes, final solidified 267 minutes, the $3 d$ compressive strength is $27.1 \mathrm{MPa}$, and the $28 \mathrm{~d}$ compressive strength is $52.3 \mathrm{MPa}$.

(4) Slaked lime: The slaked lime used in this experiment is produced in Kenya, the effective contents of $\mathrm{CaO}$ and $\mathrm{MgO}$ were $68.2 \%$.

(5) Amine anti-stripping agent: Its appearance is milky thick liquid, $\mathrm{pH}$ value is between $10 \sim 12$, freezing point is less than $0^{\circ} \mathrm{C}$, and its dosage is $0.4 \%$ of asphalt mass.

Table 1. Technical index of aggregate

\begin{tabular}{|c|c|c|c|c|c|c|c|c|}
\hline \multicolumn{5}{|c|}{ chemical composition/\% } & \multirow{2}{*}{$\begin{array}{c}\text { compressive } \\
\text { strength/MPa }\end{array}$} & $\begin{array}{c}\text { apparent density, } \\
\mathrm{kg} / \mathrm{m}^{3}\end{array}$ & $\begin{array}{c}\text { crushing } \\
\text { value } / \%\end{array}$ & soundness $/ \%$ \\
\cline { 1 - 4 } $\mathrm{SiO}_{2}$ & $\mathrm{Al}_{2} \mathrm{O}_{3}$ & $\mathrm{Fe}_{2} \mathrm{O}_{3}$ & $\mathrm{CaO}$ & $\mathrm{MgO}$ & 2672 & 10.15 & 3.2 \\
\hline 65.39 & 13.18 & 12.27 & 2.66 & 0.82 & 95.2 & 2672 & 3.2 \\
\hline
\end{tabular}

Table 2. Technical index of asphalt

\begin{tabular}{|l|c|c|c|c|}
\hline type & $\begin{array}{c}25^{\circ} \mathrm{C} \text { penetration } \\
/ 0.1 \mathrm{~mm}\end{array}$ & softening point $/{ }^{\circ} \mathrm{C}$ & $\begin{array}{c}\text { Ductility } \\
\left(15^{\circ} \mathrm{C}, 5 \mathrm{~cm} / \mathrm{min}\right)\end{array}$ & $\begin{array}{c}\text { Ductility } \\
\left(5^{\circ} \mathrm{C}, 5 \mathrm{~cm} / \mathrm{min}\right)\end{array}$ \\
\hline petroleum asphalt $70^{\#}$ & 64.2 & 49.2 & 146.1 & -- \\
\hline SBS modified asphalt & 52.6 & 86.9 & -- & 42 \\
\hline
\end{tabular}

\subsection{Testing plan}

First, without adding any anti-stripping agent, the igneous rock aggregate is directly combined with the two kinds of asphalt respectively; secondly, the igneous rock aggregate is pretreated by soaking in the saturated solution of cement or Slaked lime, and then compounded with two kinds of asphalt respectively; the third is to add $0.4 \%$ amine anti-stripping agent to the asphalt and mix well with igneous aggregate; the fourth is that igneous aggregate is pretreated by saturated solution of cement or Slaked lime, and then compounded with asphalt treated by amine anti-stripping agent. The effect of single or multiple anti-stripping agent on the adhesion of asphalt aggregate was studied.

\subsection{Test methods}

According to the method of T0616-1993 in JTU E202011, the boiling test was carried out. In order to make the test results more objective and accurate, the test improves the detection method on the basis of the standard test method, and obtains the asphalt stripping rate through formula calculation. The test method is as follows.

(1) 5 aggregates with particle size of about $16 \mathrm{~mm}$ were taken from each group, and put them into the oven to dry, then cooled to room temperature. The mass of each particle was weighed and recorded as $m_{0 n}(n=1 \sim 5)$.

(2) The suspension device is used to hang each aggregate particle separately.

(3) Heat the asphalt in an oven at about $150{ }^{\circ} \mathrm{C}$ until it is molten, immerse the suspended aggregate particles in the asphalt, then take them out and hang them to dry to room temperature, The weighed mass is recorded as $\mathrm{m}_{\text {jn }}(\mathrm{n}=1 \sim 5)$;

(4) Wrap the dried bituminous aggregate with gauze and put it in an ultrasonic wave filled with boiling water to heat it for $0 \sim 10 \mathrm{~min}$, then take it out and dry it;

(5) Take off the gauze, and then cut off the asphalt bonded on the gauze and the asphalt separated from the surface of the aggregate particles with a wallpaper knife, dry the remaining asphalt mixture to constant weight, and record the weight as $\mathrm{m}_{\mathrm{zn}}(\mathrm{n}=1 \sim 5)$;

(6) The stripping rate of asphalt was calculated to judge the adhesion performance of asphalt and aggregate particles. the calculation method was shown in formula (1):

$$
D_{i n}=\left(m_{j n}-m_{z n}\right) /\left(m_{j n}-m_{0 n}\right) \times 100 \%
$$

In the formula:

$D_{\text {in }}$ is the $n$th asphalt stripping rate for testing;

$\mathrm{m}_{0 \mathrm{n}}$ is the mass of the $\mathrm{nth}$ aggregate particle;

$\mathrm{m}_{\mathrm{jn}}$ is the total mass of the nth asphalt mixture after adhesion;

$\mathrm{m}_{\mathrm{zn}}$ is the mass of the $\mathrm{nth}$ adhesive asphalt particle after being immersed in water and shedding part of asphalt mixture.

\section{Results and Analysis}

\subsection{Study on the adhesion property of igneous rock aggregate and petroleum asphalt $70^{\#}$}

According to the four test schemes in section 1.2, igneous rock aggregate and petroleum asphalt 70 are compounded to study the stripping rate of petroleum asphalt $70^{\#}$ on the surface of moderately weathered igneous rock aggregate under different boiling time and 
different anti stripping measures. The test results are shown in table 3:

Table 3. Anti-stripping test results of igneous rock aggregate and petroleum asphalt $70^{\#}$ under different anti-stripping measures

\begin{tabular}{|c|c|c|c|c|c|c|}
\hline \multirow{2}{*}{$\begin{array}{c}\text { boiling } \\
\text { time/min }\end{array}$} & \multicolumn{6}{|c|}{ stripping rate of asphalt film/\% } \\
\cline { 2 - 7 } & Blank(A-1) & cement(A-2) & $\begin{array}{c}\text { slaked } \\
\text { lime(A-3) }\end{array}$ & $\begin{array}{c}\text { amine anti-stripping } \\
\text { agent(A-4) }\end{array}$ & $\begin{array}{c}\text { cement+amine anti- } \\
\text { stripping agent(A-5) }\end{array}$ & $\begin{array}{c}\text { slaked lime+amine anti- } \\
\text { stripping agent(A-6) }\end{array}$ \\
\hline 1 & 5 & 3 & 3 & 0 & 0 & 0 \\
\hline 2 & 28 & 7 & 6 & 0 & 0 & 0 \\
\hline 3 & 42 & 10 & 9 & 2 & 0 & 0 \\
\hline 4 & 63 & 15 & 13 & 4 & 2 & 2 \\
\hline 5 & 80 & 24 & 21 & 6 & 15 & 3 \\
\hline 6 & 94 & 29 & 26 & 22 & 22 & 22 \\
\hline 7 & 100 & 35 & 32 & 38 & 28 & 26 \\
\hline 8 & 100 & 41 & 37 & 57 & 33 & 31 \\
\hline 9 & 100 & 46 & 42 & 76 & 36 & 35 \\
\hline 10 & 100 & 49 & 44 & 83 & & \\
\hline
\end{tabular}

\subsubsection{Effect of single anti-stripping agent on adhesion property of petroleum asphalt $70^{\#}$ aggregate}

Under a single anti-stripping measure, the effect of different boiling time and different anti-stripping agents on the adhesion properties of igneous rock aggregate and petroleum asphalt $70^{\#}$ aggregate is shown in Fig. 1. It can be seen from Figure 1, with the extension of boiling time, the stripping rate of petroleum asphalt $70^{\#}$ on the surface of igneous rock aggregate increases gradually, and the stripping rate of asphalt aggregate without anti stripping agent increases rapidly with the extension of boiling time, and the asphalt film falls off completely in about 7 minutes, the adhesion performance is poor. However, the stripping rate of asphalt on the surface of igneous rock aggregate which was pretreated by cement and Slaked lime is obviously reduced, and the stripping resistance of Slaked lime is slightly better than that of cement. The main reason why both cement and lime can improve the adhesion of asphalt aggregate is that lime can react with organic acids in asphalt, the product makes the aggregate surface activate to improve the adhesion between the asphalt and the aggregate [5]. Meanwhile, slaked lime is beneficial to the formation of microporous adsorption of asphalt on the surface of aggregate and enhances the adhesion of asphalt and aggregate [6], the cement will absorb the moisture in asphalt and hydration reaction will occur, and then chemical adsorption will occur, forming a layer of film to enhance the adhesion between asphalt and aggregate [7].

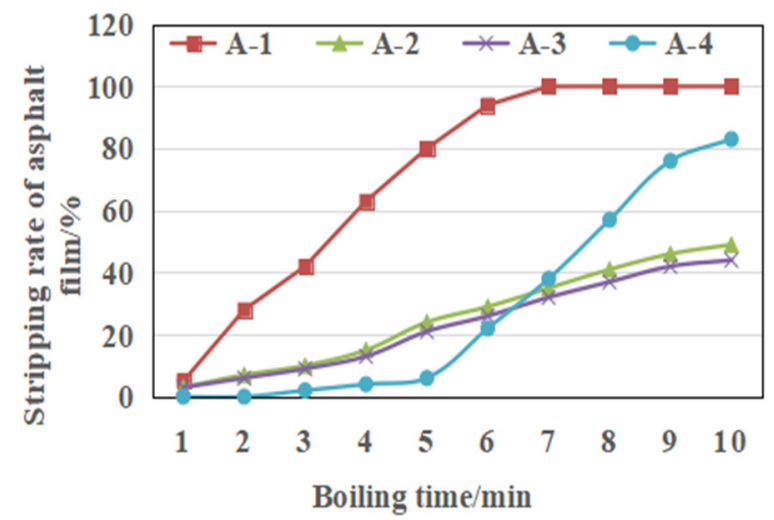

Fig. 1 Effect of different anti-stripping agents on the adhesion property of petroleum asphalt $70^{\#}$ aggregate

It can be seen from Fig. 1, the anti-stripping ability of amine anti-stripping agent is stronger than that of cement and Slaked lime before boiling for 6 minutes, with the extension of boiling time, the anti-stripping ability of amine anti-stripping agent decreases. Before boiling for 5 minutes, the stripping rate of asphalt film is low, and the anti-stripping ability is good and stable. After boiling for 5 minutes, the stripping speed of asphalt film is accelerated. The main reason is that the amine antistripping agent belongs to high molecular polymer material, which has poor heat resistance. With the extension of heating time, it is easy to decompose and lose part or all of its function.

\subsubsection{Effect of multiple anti-stripping agent on adhesion performance of petroleum asphalt $70^{\#}$ aggregate}

The influence of different boiling time and anti-stripping agent on the adhesion properties of igneous rock aggregate and petroleum asphalt $70^{\#}$ aggregate is shown in Fig. 2. It can be seen from Fig. 2, with the extension of boiling time, the stripping rate of petroleum asphalt $70^{\#}$ on the surface of igneous rock aggregate increases gradually, and the stripping resistance of asphalt aggregate with multiple anti-stripping agent is better than that of asphalt aggregate with single anti stripping agent. 
Due to the poor heat resistance of amine anti-stripping agent, the stripping resistance of asphalt aggregate which compound mixed with anti-stripping agent decreases gradually with the extension of boiling temperature, After 5 minutes, the stripping rate increased and the stripping resistance decreased, however, it is always better than adding anti-stripping agent alone.The adhesion performance of asphalt aggregate $70^{\#}$ mixed with (Slaked lime + amine anti-stripping agent) is better than that of asphalt aggregate mixed with (cement + amine anti-stripping agent).

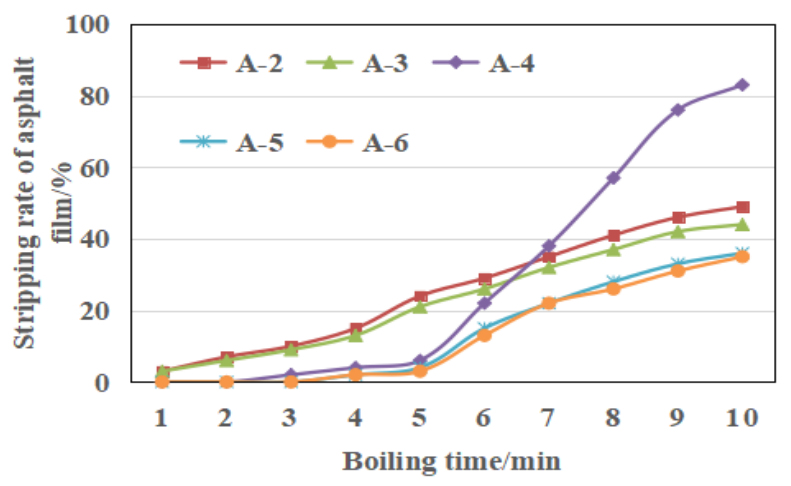

Fig. 2 Effect of multiple anti-stripping agent on adhesion performance of petroleum asphalt $70^{\#}$ aggregate

\subsection{Study on adhesion properties of igneous aggregate and SBS modified asphalt}

According to the four test schemes in section 1.2, igneous rock aggregate and SBS modified asphalt are compounded to study the stripping rate of SBS modified asphalt on the surface of moderately weathered igneous rock aggregate under different boiling time and different anti stripping measures. The test results are shown in Table 4.

\subsubsection{Effect of single anti-stripping agent on adhesion of SBS modified asphalt aggregate}

Under single anti-stripping measure, the effect of different boiling time and different anti-stripping agents on the adhesion properties of igneous rock aggregate and SBS modified asphalt aggregate is shown in Fig. 3. It can be seen from Fig. 3, with the extension of boiling time, the stripping rate of SBS modified asphalt aggregate on the surface of igneous rock aggregate increases gradually, and the stripping rate of asphalt aggregate without anti stripping agent increases rapidly with the extension of boiling time, and the asphalt film falls off completely in about 10 minutes, the adhesion performance is poor.

However, the stripping rate of asphalt on the surface of igneous rock aggregate which was pretreated by cement and Slaked lime is obviously reduced, and the stripping resistance of Slaked lime is slightly better than that of cement. Before boiling for 7.5 minutes, the antistripping ability of amine anti-stripping agent is better than that of cement and slaked lime. If the boiling time is extended, the anti-stripping ability of amine is lower than that of cement and slaked lime. For amine anti-stripping agent, boiling for 6 minutes is a turning point. Before, the stripping rate of asphalt film is low and the growth rate is slow, but after that, the stripping rate accelerates and the adhesion performance between SBS modified asphalt and igneous rock aggregate becomes worse.

Table 4 Anti-stripping test results of igneous rock aggregate and SBS modified asphalt under different anti stripping measures

\begin{tabular}{|c|c|c|c|c|c|c|}
\hline \multirow{2}{*}{$\begin{array}{c}\text { boiling } \\
\text { time/min }\end{array}$} & \multicolumn{7}{|c|}{ stripping rate of asphalt film/\% } \\
\cline { 2 - 7 } & Blank(B-1) & cement(B-2) & $\begin{array}{c}\text { slaked } \\
\text { lime(B-3) }\end{array}$ & $\begin{array}{c}\text { amine anti-stripping } \\
\text { agent(B-4) }\end{array}$ & $\begin{array}{c}\text { cement+amine anti- } \\
\text { stripping agent(B-5) }\end{array}$ & $\begin{array}{c}\text { slaked lime+amine anti- } \\
\text { stripping agent(B-6) }\end{array}$ \\
\hline 1 & 3 & 0 & 0 & 0 & 0 & 0 \\
\hline 2 & 16 & 0 & 0 & 0 & 0 & 0 \\
\hline 3 & 28 & 3 & 3 & 0 & 0 & 0 \\
\hline 4 & 40 & 8 & 7 & 2 & 0 & 2 \\
\hline 5 & 52 & 13 & 11 & 6 & 5 & 4 \\
\hline 6 & 63 & 19 & 17 & 11 & 13 & 12 \\
\hline 7 & 77 & 26 & 25 & 23 & 20 & 23 \\
\hline 8 & 86 & 33 & 31 & 35 & 25 & 27 \\
\hline 9 & 96 & 39 & 36 & 49 & 62 & 29 \\
\hline 10 & 100 & 45 & 42 & & & 2 \\
\hline
\end{tabular}




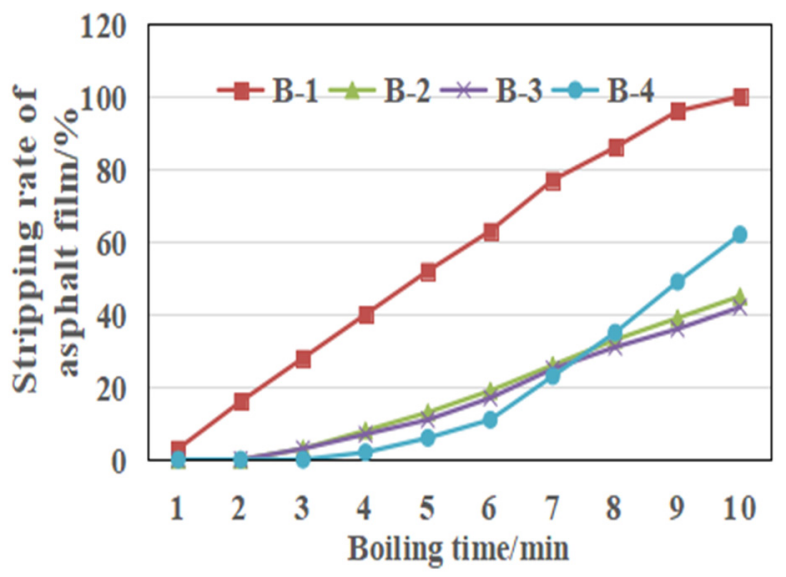

Fig. 3 Effect of different anti-stripping agents on adhesion of SBS modified asphalt aggregate

\subsubsection{Effect of multiple anti-stripping agent on adhesion of SBS modified asphalt aggregate}

The influence of different boiling time and anti-stripping agent on the adhesion properties of igneous rock aggregate and SBS modified asphalt aggregate is shown in Fig. 4. It can be seen from Fig. 4, with the extension of boiling time, the stripping rate of SBS modified asphalt on the surface of igneous rock aggregate increases gradually, and the stripping resistance of asphalt aggregate with multiple anti-stripping agent is better than that of asphalt aggregate with single anti stripping agent. For SBS modified asphalt aggregate mixed with multiple anti-stripping agent, the stripping rate of asphalt film has a turning point at 6 minutes. Before 6 minutes, the stripping rate increases slowly with boiling time, and after 6 minutes, the stripping rate increases rapidly. The adhesion performance of SBS modified asphalt mixed with (Slaked lime + amine anti-stripping agent) is better than that of asphalt aggregate mixed with (cement + amine anti-stripping agent).

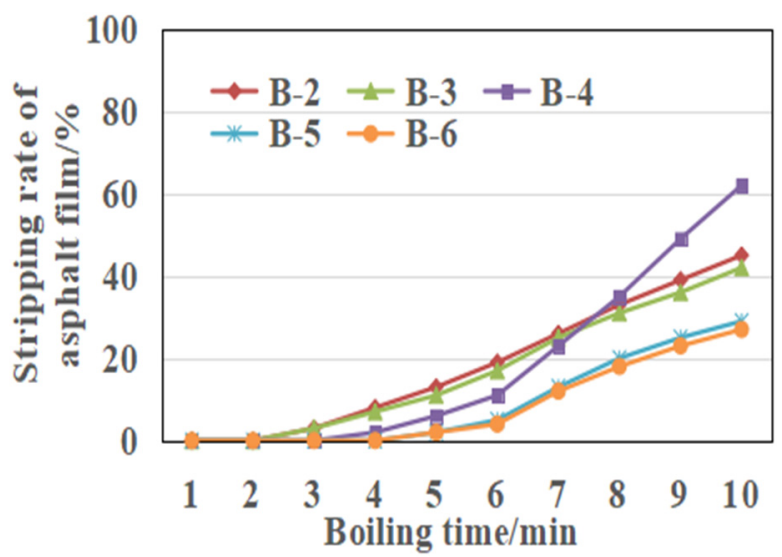

Fig. 4 Effect of fineness of boulders powder on compressive strength of concrete

\section{Conclusion}

(1) With the extension of boiling time, the stripping rate of asphalt on the surface of igneous rock aggregate increases gradually, and the adhesion between igneous rock aggregate and two kinds of asphalt is greatly improved by adding anti-stripping agent.

(2) Under the single anti-stripping measure, the antistripping ability of slaked lime is slightly better than that of cement for two kinds of asphalt aggregates, For the igneous petroleum asphalt $70^{\#}$ aggregate, the antistripping ability of amine anti-stripping agent is higher before boiling for 5 minutes, and gradually decreases with the extension of boiling time. For the igneous SBS modified asphalt aggregate, the anti-stripping ability of amine anti-stripping agent is higher before boiling for 6 minutes, and the anti-stripping ability decreases rapidly with the extension of boiling time.

(3) The results show that the igneous asphalt aggregate mixed with multiple anti-stripping agent has better adhesion than that mixed with single anti-stripping agent. The adhesion performance of asphalt aggregate mixed with (Slaked lime + amine anti-stripping agent) is better than that of asphalt aggregate mixed with (cement + amine anti-stripping agent).

\section{References}

1. Y. Wu, F. Wang, and Y. Zhang, J. China Foreign Highw. 36, 289 (2016).

2. J. Tan, West. China Commun. Sci. Technol. 21 (2018).

3. X. Zheng, Q. Yang, and W. Lv, J. Build. Mater. 480 (2005).

4. Z. Wei, Transp. Sci. Technol. 132 (2017).

5. S. Du and X. Suo, J. Xi' an Technol. Univ. 33, 982 (2013).

6. D. $\mathrm{Wu}$, The Research of Performance on Cement and Amine Anti-Stripping Material's Asphalt Mixture Pavement, Dissertation, Chongqing Jiaotong University, 2016.

7. Z. Wang, A. Sha, J. Xiao, and S. Du, J. Wuhan Univ. Technol. 31, 16 (2009). 